\title{
APROXIMAÇÕES ENTRE CURADORIA DIGITAL E CAQDAS: UMA REVISÃO SISTEMÁTICA DE LITERATURA
}

\author{
SYSTEMATIC REVIEW OF THE LITERATURE ON DIGITAL CURATORSHIP WITH
} THE SUPPORT OF DIGITAL TOOLS

\section{APROXIMACIONES ENTRE CURADURÍA DIGITAL Y CAQDAS: UNA REVISIÓN SISTEMÁTICA DE LA LITERATURA}

\author{
Katia Alexandra de Godoi e Silva \\ Universidade Anhanguera Uniderp - Brasil \\ Universidade Pitágoras Unopar - Brasil \\ António Pedro Costa \\ Universidade de Aveiro - Portugal
}

\begin{abstract}
Resumo: Este artigo propõe contribuir para a reflexão sobre o processo de curadoria digital, no intuito de discorrer sobre algumas das principais concepções sobre curadoria digital em diferentes contextos, tanto por autores brasileiros quanto estrangeiros, de modo a elucidar e aproximar o tema na organização e gestão de dados em Computer Assisted Qualitative Data Analysis Software (CAQDAS). Para alcançar tal objetivo, esta pesquisa se utilizou de metodologia qualitativa de cunho descritivo, possibilitada por uma revisão sistemática da literatura de trabalhos científicos sobre o tema da curadoria digital, a partir de buscas em uma base de dados acadêmicas (Scopus) e em uma base da literatura cinzenta (Banco de Teses e Dissertações da Coordenação de Aperfeiçoamento de Pessoal de Nível Superior - CAPES). Como resultados, constatou-se que as concepções sobre curadoria digital convergem para diferentes práticas de curadoria de conteúdo, curadoria digital de dados de pesquisa ou eScience e curadoria digital. Também constatou-se que a curadoria digital pode ser aplicada em diferentes contextos, como bases de dados colaborativas, redes sociais, repositórios, gerenciadores de dados qualitativos, preservação do acervo de objetos culturais digitais, além da organização de dados qualitativos em CAQDAS e também como proposta metodológica no processo de ensino.
\end{abstract}

Palavras chave: Curadoria Digital; CAQDAS; Pesquisa Qualitativa.

\begin{abstract}
This article proposes to reflect on the digital curation process in order to discuss some of the leading conceptions about digital curation in different contexts, both by Brazilian and foreign authors, in order to elucidate and approach the theme in the organization and management of data in ComputerAssisted Qualitative Data Analysis Software (CAQDAS). To achieve this goal, the researchers used a qualitative methodology. Of a descriptive nature, made possible by a systematic review of the literature of scientific works on the subject of digital curation. From searches in an academic database (Scopus) and in a database gray literature (Bank of Theses and Dissertations of the Coordination for the Improvement of Higher Education Personnel - CAPES). As a result, digital curation concepts converge to different practices of content curation, digital curation of research data or eScience and digital curation. It was also found that digital curation can be applied in different contexts: as collaborative databases, social networks, repositories, qualitative data managers, preservation of the collection of
\end{abstract}


digital cultural objects, and the organization of qualitative data in CAQDAS and as a methodological proposal in the teaching process.

Keywords: Digital Curation; CAQDAS; Qualitative research.

Resumen: Este artículo propone reflexionar sobre el proceso de curación digital, con el fin de discutir algunas de las principales concepciones sobre la curación digital en diferentes contextos, tanto de autores brasileños como extranjeros, con el fin de dilucidar y abordar el tema en la organización y gestión de datos en Software de análisis cualitativo de datos asistido por computadora (CAQDAS). Para lograr este objetivo, esta investigación utilizó una metodología cualitativa de carácter descriptivo, posibilitada por una revisión sistemática de la literatura de trabajos científicos en el tema de la curación digital, a partir de búsquedas en una base de datos académica (Scopus) y en una base de datos de literatura gris (Banco de Tesis y Disertaciones de la Coordinación para el Perfeccionamiento del Personal de Educación Superior - CAPES). Como resultado, se encontró que los conceptos de curación digital convergen en diferentes prácticas de curación de contenido, curación digital de datos de investigación o eScience y curación digital. También se encontró que la curación digital se puede aplicar en diferentes contextos, como bases de datos colaborativas, redes sociales, repositorios, gestores de datos cualitativos, preservación de la colección de objetos culturales digitales, además de la organización de datos cualitativos en CAQDAS y también como una propuesta metodológica en el proceso docente.

Palabras clave: Curación digital; CAQDAS; Investigación cualitativa.

\section{Introdução}

A internet, a partir do seu crescimento e desenvolvimento ao longo dos anos, cristalizou com sua base de dados a condição básica da sociedade da informação: "a superabundância de informação de todos os tipos" (MANOVICH, 2001, p. 35). Mello (2015) argumenta que esse excesso de informação "faz com que a estrutura hipertextual da internet não seja suficiente para o acesso à informação, trazendo como consequência a busca, e a criação, de filtros que facilitam esse processo" (p. 9). Assim, a escolha e organização de dados qualitativos da pesquisa científica é afetada por essa complexidade de informações, envolvendo dilemas éticos que perpassam a pesquisa em educação, pois a conduta ética deve ser uma preocupação constante do pesquisador, em qualquer das etapas de sua investigação.

Ademais, observa-se que nos últimos anos tem ocorrido um crescente desenvolvimento e interesse, por parte dos pesquisadores, pelas abordagens de investigação qualitativa no contexto digital, que sejam capazes de incorporar as características específicas e complexas desses contextos e, ao mesmo tempo, aprimorar o rigor científico. Desta forma, o uso de software em investigações científicas de base qualitativa tem ganhado importante reconhecimento no cenário científico, tanto no desenvolvimento de estratégias de revisão de literatura quanto na organização, coleta, análise e triangulação de dados (SOUZA; COSTA; 
MOREIRA, 2011; SOUZA, et al. 2011a; 2011b; 2015; SILVA; ALMEIDA, 2017) e, consequentemente, influenciando o design da investigação qualitativa.

Para além desse interesse, conforme descreve Valente (2015), as tecnologias digitais também criaram novas fontes de dados digitais (p. ex.: as listas e fórum de discussão, páginas da web e redes sociais), bem como novas formas de coleta de dados que incluem gravações digitalizadas e entrevistas on-line, assim como alterou os procedimentos de gerenciamento da pesquisa. Tudo isso, revelou possibilidades dinâmicas para novos projetos e enfoques de diferentes estudos.

Nessa perspectiva, a intenção é provocar reflexões na comunidade de pesquisadores, em um contexto, segundo Barros e Marcondes $(2019$, p. 2) "de pouca produção acerca do tema para o público específico de educadores que, muitas vezes, pesquisam em seu próprio local de trabalho", assim como de diferenciar-se de pesquisas sobre o tema, no sentido de abordar as premissas éticas que envolvem um projeto, desde o seu design inicial até a divulgação de resultados.

Observa-se também, nos últimos anos, que pesquisadores têm procurado incorporar os desenvolvimentos tecnológicos, mais especificamente a utilização de programas dedicados, como CAQDAS, que têm sido extremamente úteis para a gestão de dados e apoio aos processos de codificação (LAGE; GODOY, 2008; VALENTE, 2015; DE ALMEIDA; FREITAS; COSTA; MOREIRA, 2019).

Esta tipologia de software se destaca e são procurados porque possibilitam que a análise qualitativa seja, segundo Andrade, Costa, Linhares, Almeida e Reis (2018, p. 279, tradução nossa), "realizada em diversos formatos (áudio, vídeo, imagem, texto), níveis de trabalho colaborativo (individual, duas pessoas trabalhando ao mesmo tempo ou mais de duas) e com possibilidades distintas de organização dos dados pesquisados".

O webQDA (COSTA; MOREIRA; SOUZA, 2019), por exemplo, permite apoiar o tratamento dos dados coletados, a codificação interpretativa e descritiva, além de controlar, filtrar e questionar os dados, com o objetivo de responder às questões que emergem na investigação (SOUZA; SOUZA; COSTA, 2016; SILVA; ALMEIDA, 2017; SILVA; COSTA, 2019; MINAYO; COSTA, 2019). Estes autores consideram que, apesar do software apresentarse de forma "vazia", pode ser configurado de acordo com as necessidades do investigador, além de permitir que os dados possam ser analisados e triangulados por vários investigadores num ambiente online de trabalho colaborativo. Desta forma, o programa não se direciona para um tipo específico de desenho de investigação, podendo o investigador explorar diferentes espaços, 
métodos, técnicas e cenários de pesquisa, assim como permite a edição, visualização, interligação e organização de documentos.

Apesar da utilização de CAQDAS, há pesquisadores, que utilizando tanto a abordagem qualitativa como quantitativa nas suas pesquisas, que têm lançado luz sobre problemas que estavam despercebidos, ou seja, problematizando sobre: a) como vem sendo realizada a gestão de dados das pesquisas; b) sua preservação; c) seu reuso, d) entre outros aspectos que envolvem, por exemplo, a ética nas pesquisas. Além desses problemas, outros podem ser referidos associados aos pacotes de software de análise de dados qualitativos como por exemplo, a funcionalidade de trabalho colaborativo (a qual envolve questões relacionadas aos dados compartilhados), a reutilização de dados científicos, o anonimato ou a confidencialidade, entre outros aspectos, cujo processo de ponderação e resposta a estes problemas se pode designar por curadoria digital.

Segundo Weber (2017), a curadoria digital emerge como um campo de pesquisa e prática interdisciplinar que reflete uma abordagem holística para o gerenciamento e preservação de materiais no formato digital, abarcando assim, todo o ciclo de vida do material, tendo a preservação digital como um ponto específico deste ciclo. Para Sayão e Sales (2012), a curadoria digital surge como uma área de práticas e de pesquisa de espectro amplo que dialoga com várias disciplinas e diferentes profissionais, assim como diversos contextos. É uma área ainda em construção "Isto porque, como se trata de uma área que só recentemente despontou como crítica para a pesquisa, ainda restam muitas lacunas práticas e teóricas a serem equacionadas, orientadas, preferencialmente, por uma abordagem multidisciplinar" (SAYÃO; SALES, 2012, p. 189).

Tendo em vista essas lacunas, o objetivo do presente estudo reside em contribuir para a reflexão sobre o processo de curadoria digital, no intuito de discorrer sobre algumas das principais concepções sobre curadoria digital em diferentes contextos, de modo a elucidar e aproximar o tema na organização e gestão de dados em CAQDAS. Nessa perspectiva, este artigo, com abordagem qualitativa, busca contribuir, mesmo que de forma exploratória, para a reflexão sobre a curadoria digital em CAQDAS, temática ainda pouco discutida na Educação.

\section{Percurso metodológico: revisão sistemática da literatura}

Com vistas a alcançar o objetivo proposto e fazer essa aproximação entre o processo de curadoria digital e a análise de dados qualitativos envolvendo CAQDAS, este artigo utiliza a metodologia qualitativa de caráter descritivo e interpretativo (CRESWELL, 2010), embasada 
em uma revisão sistemática da literatura de artigos acadêmicos, teses e dissertações sobre o tema, a partir de buscas em uma base de dados acadêmicas (Scopus) e em uma base da literatura cinzenta (Banco de Teses e Dissertações da Coordenação de Aperfeiçoamento de Pessoal de Nível Superior - CAPES). Desta forma, a seguir, explicamos o planejamento e a condução da pesquisa online da revisão sistemática da literatura.

\subsection{Planeamento da revisão sistemática da literatura}

A revisão sistemática da literatura é um processo de pesquisa baseado em evidências da literatura científica, conduzida por meio de protocolo. Assim, é imprescindível que sejam registradas todas as etapas: “[...] não só para que esta possa ser replicável por outro investigador, como também para se aferir que o processo em curso segue uma série de etapas previamente definidas e absolutamente respeitadas nas várias etapas" (RAMOS; FARIA; FARIA, 2014, p. 23).

E, a finalidade é delimitar, clarificar e caracterizar o objeto de estudo, realizada por meio de levantamento bibliográfico seletivo, restrita aos estudos e parâmetros próximos às especificidades do interesse do pesquisador (NÓBREGA-THERRIEN; THERRIEN, 2004). Para o recorte deste estudo, a partir dos estudos de Gouch et al. (2012), Saur-Amaral (2010) e Silva et al. (2020), foram adotados os seguintes passos, conforme mostra o Quadro 1, no intuito de exemplificar o processo de revisão sistemática da literatura a ser realizado no decorrer deste estudo.

Quadro 1 - Etapas do processo de revisão sistemática da literatura

Objetivo e Questão de Contribuir para a reflexão sobre o processo de curadoria digital, no intuito investigação

de discorrer sobre algumas das principais concepções sobre curadoria digital em diferentes contextos, de modo a elucidar e aproximar o tema na organização e gestão de dados em CAQDAS.

Quais aproximações podem ser estabelecidas entre curadoria digital e gestão de dados em CAQDAS?

\begin{tabular}{|l|l|}
\hline $\begin{array}{l}\text { Equações de } \\
\text { pesquisa }\end{array}$ & $\begin{array}{l}\text { Digital AND curation; digital AND curation AND cloud AND software; } \\
\text { "qualitative analysis" AND curation; curation AND software. }\end{array}$ \\
\hline Âmbito da pesquisa & $\begin{array}{l}\text { Scopus e Banco de Teses e Dissertações da Coordenação de } \\
\text { Aperfeiçoamento de Pessoal de Nível Superior (CAPES). }\end{array}$ \\
\hline $\begin{array}{l}\text { Critérios de } \\
\text { inclusão }\end{array}$ & $\begin{array}{l}\text { Artigos publicados em periódicos científicos. } \\
\text { Teses e dissertações disponíveis no Catálogo de Teses e Dissertações da } \\
\text { CAPES. } \\
\text { Artigos, teses e dissertações nas áreas das Ciências Sociais e Ciência da } \\
\text { Computação. }\end{array}$ \\
\hline $\begin{array}{l}\text { Critérios de } \\
\text { exclusão }\end{array}$ & $\begin{array}{l}\text { Artigos sem resumo. } \\
\text { Artigos publicados em outras fontes e fora do âmbito das Ciências Sociais }\end{array}$ \\
\hline
\end{tabular}




\begin{tabular}{|l|l|}
\hline \multicolumn{1}{|c|}{$\begin{array}{l}\text { e Ciência da Computação e que não sejam em português e/ou inglês. } \\
\text { Trabalhos científicos que não contemplavam o tema de interesse, isto é, } \\
\text { que não abordam o conceito de curadoria. }\end{array}$} \\
\begin{tabular}{|l} 
de validade \\
metodológica
\end{tabular} & $\begin{array}{l}\text { Replicação do processo por dois pesquisadores, para verificação dos } \\
\text { critérios de inclusão e exclusão. }\end{array}$ \\
\hline Resultados & $\begin{array}{l}\text { Descrição da pesquisa e registro de todos os passos. } \\
\text { Apresentação dos dados. }\end{array}$ \\
\hline $\begin{array}{l}\text { Tratamento de } \\
\text { dados }\end{array}$ & $\begin{array}{l}\text { Filtrar, analisar e descrever criticamente os resultados, a partir dos } \\
\text { seguintes aspectos: concepções sobre curadoria; e contextos de utilização } \\
\text { da curadoria digital. }\end{array}$ \\
\hline
\end{tabular}

Fonte: Organizado pelos autores.

Fornari, Pinho e Costa (2019) relatam que a revisão sistemática da literatura vem sendo explorada, cada vez mais, como um trabalho colaborativo entre pesquisadores, considerandose a necessidade de lidar com o crescente volume de informações e da sua seleção. Neste sentido, a otimização do processo da revisão pode apoiar-se em ferramentas digitais de suporte às pesquisas.

\subsection{Condução da pesquisa online}

A partir da utilização de ferramentas digitais e para o recorte deste estudo, a presente pesquisa foi desenvolvida em duas fases. Na primeira fase, utilizamos a base de dados da Scopus e o Banco de Teses e Dissertações da CAPES.

$\mathrm{Na}$ segunda fase, utilizamos o webQDA, um software de apoio à análise de dados qualitativos, pois com o webQDA, o pesquisador pode editar, visualizar, interligar e organizar documentos, além disso o pesquisador pode criar categorias, codificar, controlar, filtrar, procurar e questionar os dados com o intuito de responder às questões que emergem na sua investigação (COSTA; MOREIRA; SOUZA, 2019).

A primeira fase da pesquisa foi realizada entre março e abril de 2021. Na revisão foram incluídos estudos publicados na língua inglesa e portuguesa. Conforme mencionamos no Quadro 1, a busca foi realizada em duas bases de dados acadêmicos (Scopus e Catálogo de Teses e Dissertações da CAPES).

Para essa revisão de literatura foi definida e utilizada a seguinte estratégia de pesquisa: digital AND curation; digital AND curation AND cloud AND software; "qualitative analysis" AND curation; curation AND software, nas áreas das Ciências Sociais e Ciência da Computação. 
O corpus de análise surgiu a partir da coleta de dados inicial ( 8 artigos e 25 teses ou dissertações, totalizando 33 trabalhos científicos). Após a verificação dos artigos, houve uma seleção dos estudos de acordo com os critérios de exclusão descritos no Quadro 1 (totalizando 16 trabalhos científicos) e ficaram então 6 artigos e 10 teses ou dissertações. (Figura 1)

Figura 1 - Fluxograma da coleta de dados

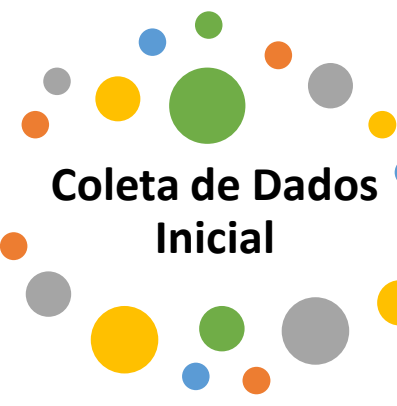

- 8 artigos

- 25 teses ou dissertações

\section{Critérios de exclusão}

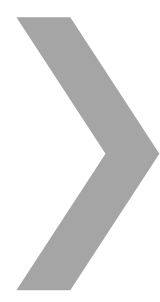

- 6 artigos

- 10 teses ou dissertações

Fonte: Organizado pelos autores

Vale considerar que, apesar do interesse na aproximação da temática da curadoria digital e os CAQDAS, não encontramos resultados ao utilizarmos os seguintes descritores e operadores booleanos em inglês: "digital curation" AND "qualitative analysis"; digital AND curation AND cloud AND software; "qualitative analysis" AND curation.

Entretanto, encontramos investigações científicas que se aproximam da discussão da abordagem qualitativa, a partir do descritor: "digital curation" AND "qualitative analysis".

Após a seleção dos 16 trabalhos científicos na revisão, foram salvos em formato Portable Document Format (.pdf) e organizados no webQDA. Essa decisão justifica-se devido aos autores estarem familiarizados e serem colaboradores desta ferramenta, além da possibilidade de trabalhar colaborativamente, na organização e definição dos conceitos de análises.

Posteriormente à organização procedeu-se à análise dos trabalhos encontrados e foram criadas notas específicas para cada um (fonte interna no webQDA). As notas abordaram os conceitos sobre curadoria, os objetivos e as abordagens metodológicas propostas pelos autores.

As notas elaboradas foram transformadas em duas temáticas: concepções sobre curadoria; e contextos de utilização da curadoria digital, as quais foram interpretadas no presente estudo. 


\section{Revisão sistemática da literatura - análise e discussão}

A amostra documental, constituída pelos 16 trabalhos científicos selecionados, foi objeto de uma análise segundo dois eixos que irão ser discutidos nos próximos tópicos. $\mathrm{O}$ primeiro tema relata as concepções sobre curadoria digital adotadas pelos autores. $\mathrm{O}$ segundo apresenta os contextos de utilização da curadoria digital nas pesquisas. (Quadro 2)

Quadro 2-Temas e subtemas

\begin{tabular}{ll}
\hline Temas & Subtemas \\
\hline $\begin{array}{l}\text { [1] Concepções sobre } \\
\text { curadoria digital }\end{array}$ & \\
\hline & $\begin{array}{l}\text { [a] Abordagens [curadoria de conteúdo; curadoria digital de } \\
\text { dados de pesquisa ou eScience; curadoria digital] }\end{array}$ \\
\hline [b] Ações previstas pelo Modelo do Ciclo de Vida da \\
Curadoria Digital [conceituar; criar; acessar e usar; avaliar e \\
selecionar; descartar; ingerir; preservar; reavaliar; armazenar; \\
acessar e reutilizar; transformar]
\end{tabular}

Fonte: Organizado pelos autores.

\subsection{Concepções sobre curadoria digital}

O presente estudo identificou que todos os artigos, teses e dissertações analisados, apresentam concepções sobre curadoria digital. Antes mesmo de trazer a definição do conceito de curadoria digital, Silva (2017) explica que o termo curadoria tem sua origem no latim "curatelae", que significa, ato de curar, zelar algo. Este termo remete a outro bastante parecido que é o de "curator", que quer dizer aquele que administra, aquele que tem cuidado e apreço. Ambos os termos são usados em várias áreas do conhecimento e em diferentes espaços. Da mesma forma, Barton (2018) revela que este conceito de curadoria digital pode ser utilizado de muitas maneiras em relação às práticas analógicas e digitais. A origem do termo está em instituições como museus, bibliotecas e galerias de arte, assim como em outras áreas, onde exposições e coleções são vistas como curadoria. Esses conceitos, analógicos ou digitais, convergem para práticas de letramento, atividades de escolha, seleção, edição, organização, 
categorização, catalogação, revisão, conexão, classificação, refinamento, arquivamento, criação de um registro, entre outros aspectos.

Santos (2014), na sua revisão de literatura, identificou três abordagens: a curadoria de conteúdo; a curadoria digital de dados de pesquisa ou eScience; a curadoria digital. A primeira abordagem, a curadoria de conteúdo, está relacionada ao ato de encontrar, reunir e disponibilizar conteúdos digitais que envolvam um determinado tema, de forma organizada. Procurando abordar a aproximação da curadoria digital de conteúdo, o estudo de Chagas, Linhares e Mota (2019) trata da concepção sobre a prática da curadoria de conteúdo digital, a qual "emergiu do uso que os próprios docentes/pesquisadores já fazem da curadoria de conteúdo no processo de ensino-aprendizagem a partir de temáticas que o interessam, ou as quais necessita aprofundar-se" (CHAGAS, LINHARES; MORA, 2019, p. 34). Nessa perspectiva, os autores argumentam que o conceito de curadoria está relacionado aos elementos de uma aprendizagem ativa e o advento da cibercultura, fez emergir um novo dilema docente, "como autorizar os discentes a se tornarem ativos no processo de ensino-aprendizagem, através do uso da curadoria de conteúdo digital, que orienta a busca no ciberespaço dos conteúdos necessários para a resolução de problemas relacionados a sua profissão" (CHAGAS, LINHARES; MORA, 2019, p. 34).

A segunda abordagem, trata do termo curadoria digital de dados de pesquisa ou eScience, segundo Santos (2014), Marques (2014) e Resende (2019), e foi debatido, pela primeira vez, em um seminário de e-Science 2001. A curadoria de dados de pesquisa está cada vez mais em evidência, pois implica na preservação, mas também na manutenção de banco de dados, os quais podem ser disponibilizados, para outros pesquisadores, para a produção de novos resultados de pesquisa. Além disso, a curadoria digital de dados de pesquisa envolve cooperação, colaboração e interdisciplinaridade, assim como o registro do contexto e do histórico dos materiais digitais, tendo em vista que tais materiais podem ter diversas versões, pode estar armazenado em lugares diferentes, pode precisar de softwares específicos e pode ter ligação com outros documentos que atestem a veracidade de seu conteúdo (MARQUES, 2014; RESENDE, 2019).

Os estudos de Kirilova e Karcher (2017) sobre as práticas de Gerenciamento de Dados de Pesquisa (RDM), por professores universitários, revelam alguns fatores significativos sobre as concepções de curadoria digital, ou seja, reflexões relacionadas à quantidade de dados de pesquisa produzidos, o suporte necessário para a curadoria de dados e sua disposição em compartilhá-los. Além disso, os professores relatam que sentiram necessidade de formação quanto ao armazenamento e segurança dos dados, melhorando a qualidade do backup, suporte 
para armazenamento e preservação, indicando a necessidade de um repositório central da universidade.

Essa reflexão vai ao encontro dos estudos de Kirilova e Karcher (2017), os quais descrevem algumas opções de gerenciamento de dados em um Repositório de Dados Qualitativos (QDR), como a desidentificação e a aplicação de controles de acesso. A concepção de curadoria digital nesse estudo é compreendida pelo trabalho de uma equipe, que, neste caso, trabalhou em estreita colaboração com os pesquisadores no desenvolvimento de um protocolo de regras de anonimato. De modo geral, as atuais prescrições da QDR baseiam-se em tentar maximizar os chamados "Cinco Cofres": projetos seguros; configurações de segurança; saídas seguras; dados seguros; trabalhando com outras pessoas (CORTI; WELPTON, 2015).

A terceira abordagem refere-se, segundo Silva (2017) e Souza (2018), à curadoria digital, a qual extrapolou a gestão dos dados científicos e passou a ser empregada em todos os dispositivos que trabalham com a informação digital, ou seja, que necessitam de seleção, armazenamento, classificação e análise. Desta forma, o conceito amplia-se para todo o processo de gestão de materiais digitais. Por isso, a curadoria de dados e a curadoria digital têm conceituações próximas, assim como utilizam a mesmas vertente apoiada pelo Modelo do Ciclo de Vida da Curadoria Digital (Digital Curation Center, 2019), uma iniciativa, de 2003, do Joint Information Systems Committee (JISC), juntamente com o eScience Core Programme.

Os estudos de Santos (2014), Machado (2015), Souza (2016), Silva (2017), Souza (2018), Barton (2018), Kanke (2019) e Santos (2019), mostram que as concepções sobre curadoria digital estão diretamente relacionadas às atividades propostas no Modelo do Ciclo de Vida da Curadoria Digital (Digital Curation Center, 2019), pois trata-se de um modelo com etapas detalhadas sobre as várias atividades que envolvem o processo de curadoria.

Para o Digital Curation Center (DCC) (2019), a Curadoria Digital (CD) é um processo complexo, contínuo e interdisciplinar, que envolve a manutenção, preservação, avaliação, reavaliação, o uso e reuso, assim como a agregação de valores aos dados da pesquisa digital, por todo seu ciclo de vida. Em outras palavras, refere-se a uma preocupação em manter a qualidade original da informação a ser preservada.

O modelo de ciclo de vida da CD, proposto por Higgins (2008) (Figura 2) e adotado pelo DCC, prevê ações genéricas de CD que podem ser aplicadas em diferentes contextos. $\mathrm{O}$ modelo sistematiza as ações de curadoria, as quais podem ou não ser aplicadas em sua totalidade; no entanto, necessita de uma equipe interdisciplinar que se envolva no processo (Nakano, 2019). 
Figura 2 - Baseado no ciclo de vida da curadoria digital (Higgins, 2008)

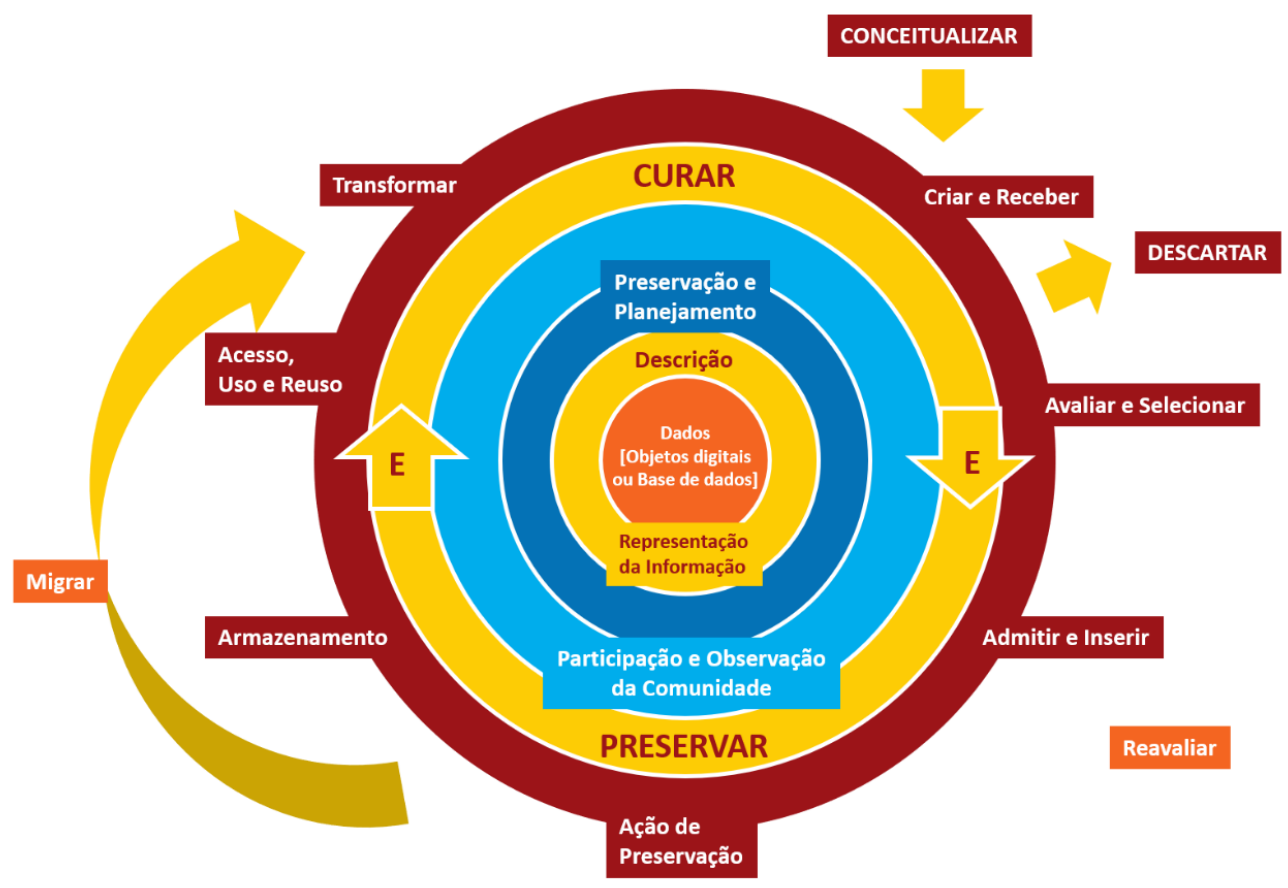

Fonte: Organizado pelos autores

As ações previstas na CD, de acordo com o modelo do DCC, podem incluir: conceituar; criar; acessar e usar; avaliar e selecionar; descartar; ingerir; preservar; reavaliar; armazenar; acessar e reutilizar; transformar.

Barton (2018), explica que as atividades que envolvem a curadoria digital são diversas, mas ao mesmo tempo são diferentes, na medida em que a criação original é importante. Assim, Barton $(2018$, p. 4) identificou um conjunto de palavras que contribuem para o complexo conceito de curadoria digital, as quais são organizadas em cinco etapas, que se sobrepõem: criação (aprimorar, reaproveitar, montar, recontextualizar, agregar); seleção (filtrar, escolher, reunir, coletar, montar, acumular, desejar); organização (vincular, arquivar, catalogar, editar, conectar, interpretar, gerenciar, classificar); apresentação (compartilhar, divulgar, exibir, distribuir, recomendar); interpretação (ensinar, proteger, cuidar, ajudar, editorializar). Segundo Barton (2018), a ideia da curadoria digital vem emergindo como uma nova área, em função da crescente preocupação da preservação, uso, reuso e compartilhamento desses materiais. Desta forma, também vem se espalhando rapidamente por diferentes contextos, dentre eles, os CAQDAS.

Uma análise sobre os desafios da pesquisa qualitativa, frente às Tecnologias Digitais de Informação e Comunicação (TDIC), é trabalhada nos estudos de Davidson (2012). Apesar do enfoque da pesquisa, vale pontuar, que esse estudo tem aderência com o interesse da presente pesquisa, pois aproxima o conceito de curadoria digital e CAQDAS, tendo em vista que no 
decorrer do estudo, a autora explica o projeto de um jornal, a partir da combinação entre o uso de software de análise de dados qualitativos (NVivo), com a pesquisa baseada em artes, por meio do uso de diários pessoais (autoetnografia). Nesse processo, Davidson (2012) identificou cinco estágios: criação de dados; organização de dados por meio do NVivo; análise das abordagens às respostas primárias; análise das respostas secundárias; por fim, o processo de curadoria. Nesse último estágio, a autora explica sua concepção sobre curadoria digital, que está articulada à utilização da tecnologia e da arte juntas, em uma pesquisa qualitativa, a qual ela denominou de "curadoria", em outras palavras, o reconhecimento sobre a importância de "pensar com as coisas".

\subsection{Contextos de utilização da curadoria digital}

A pesquisa de Kanke (2019) traz o contexto de investigação sobre como os editores participam do Wikidata e como organizam seu trabalho. Kanke $(2019$, p. 1) explica que o "Wikidata é um banco de dados multilíngue colaborativo gratuito que coleta dados estruturados para projetos da Wikimedia". Por isso, existem muitas razões para o interesse em estudar esses ambientes colaborativos, incluindo popularidade a longo prazo, histórias de edição disponíveis publicamente, estrutura e identificação de colaboradores. Além disso, os autores identificaram desafios relacionados à permanência bem-sucedida dessas, os quais são: iniciar novas comunidades, lidar com os recém-chegados, estimular a contribuição, estimular o comprometimento e regular o comportamento.

Tendo em vista tal objetivo e os apontamentos da fundamentação teórica na metodologia, o autor utilizou a análise de conteúdo, envolvendo as atividades de curadoria no contexto do Wikidata. De modo geral, os resultados revelam seis atividades: conceituar o processo de curadoria, avaliar materiais, ingerir objetos de fontes externas, criar infraestrutura colaborativa, reorganizar a infraestrutura colaborativa e acolher os recém-chegados. Desta forma, muitas das normas e regras que foram identificadas auxiliaram na regulação das atividades no Wikidata.

Outro contexto advém dos estudos de Barton (2018), que trata da curadoria digital de fotografias. Neste caso, especificamente explora a variedade de uso que as pessoas fazem do recurso de marcação no site de compartilhamento de fotos Flickr. De modo geral, as marcações são usadas da seguinte forma: identificar informações existentes em uma foto; adicionar novas informações relevantes; expressar postura afetiva em relação às imagens; abordar públicos específicos; para jogos criativos; entre outras possibilidades. Para Barton (2018), essas práticas aproximam-se do conceito de curadoria. Para o autor a noção de curadoria captura uma forma 
importante de participação no Flickr, e a curadoria online envolve um conjunto distinto de práticas de letramento.

Silva (2017), Souza (2018) e Maia (2019) discutem a transformação que se deu na produção e preservação da memória do patrimônio cultural na sociedade contemporânea, imersa nos recursos tecnológicos digitais, assim como, a curadoria digital pode contribuir para a consolidação de um movimento de fomento do reuso e apropriação cultural dos seus acervos digitais.

Silva (2017) traz uma reflexão sobre a curadoria digital no contexto da preservação do acervo de objetos culturais digitais de dois projetos, os quais estavam disponíveis na plataforma Tainacan e integrados ao aplicativo de gerenciamento de conteúdo para web, o Wordpress. O primeiro refere-se ao "Do Buraco ao Mundo" - segredos, rituais e patrimônio de um quilomboindígena e, o segundo, ao Arquivo de Som e Imagem Dalva Damiana de Freitas -, ambos possuindo textos, áudios e vídeos. Esses projetos fizeram parte do Memorial Digital do Projeto Afrobrasileiro, projeto contemplado pelo edital "Preservação e Acesso aos Bens do Patrimônio Afrobrasileiro".

Para a análise dos objetos culturais dos dois projetos, Silva (2017) utilizou o modelo de ciclo de vida de Curadoria Digital, a partir de informações contextuais, relacionadas aos seguintes aspectos: fonte do objeto cultural; tipo de objeto; miniatura utilizada em imagem ou vídeo; descrição do objeto cultural; licença de uso; tags identificadoras; campo genérico de metadados, onde o interagente poderia incluir informações; campo para relacionar objetos culturais diferentes pertencentes ao mesmo acervo; enviado por; data do envio; nome do acervo ao qual o objeto cultural pertence.

Souza (2018) traz uma reflexão sobre os objetos digitais culturais, no contexto das instituições museológicas, mais especificamente a Rede Web de Museus do Estado do Rio de Janeiro. Uma das grandes contribuições dos acervos digitais culturais é a colaboração, a socialização, o compartilhamento de dados e o reuso em diferentes situações, de modo que os itens digitais não fiquem restritos às análises de seu contexto original, mas possam expandir e alcançar novas audiências, movimentando o fluxo de informações por meio de novos canais de comunicação, assim como múltiplos acessos em diversos lugares e em diferentes momentos.

Maia (2019) tem como foco o contexto da Biblioteca José Garcia de Souza, do Museu Aeroespacial (MUSAL). Assim como Silva (2017), Maia (2019) também aplicou o modelo de ciclo de vida de Curadoria Digital desenvolvido pelo Digital Curation Centre (DCC), no planejamento da criação da biblioteca digital. A curadoria digital surgiu como uma possibilidade de equacionar e solucionar a complexidade no planejamento para a implantação 
de uma biblioteca digital, além de clarificar os questionamentos em torno da fragilidade intrínseca aos materiais digitais.

De modo geral, os estudos de Maia (2019), Souza (2018) e Silva (2017) revelaram que o modelo de ciclo de vida da curadoria digital do DCC pode ser aplicado aos objetos digitais como auxílio na definição dos elementos necessários à gestão de coleções digitais, além de possibilitar novos horizontes para um acervo.

As pesquisas de Chagas, Linhares e Mota (2019) relatam sobre o processo de curadoria de conteúdo digital no contexto da educação enquanto prática docente.

[...] curadoria de conteúdos digitais foi utilizado como forma de autorizar os alunos a se tornarem protagonistas no processo de aprendizagem. Tendo o objetivo de sugerir dispositivos metodológicos multirreferenciais para a identificação do perfil das competências informacionais dos discentes, do curso de Comunicação Social da Universidade Tiradentes. (CHAGAS; LINHARES; MOTA, 2019, p. 32).

Para atingir tal objetivo, os autores utilizam algumas estratégias para coleta de dados: "uma atividade descritiva para resolução de problema; um questionário para identificar o perfil das competências informacionais; uma oficina e a prática inicial de curadoria de conteúdo" (p. 32), as quais foram organizadas e analisadas, a partir da utilização do software webQDA. Como principal resultado, os autores observaram o desenvolvimento de habilidades, nos alunos, na realização de busca de conteúdos, fato que contribuiu na prática da curadoria de conteúdo digital.

Ainda no contexto educacional, mas diferente da abordagem anterior, que trata da curadoria de conteúdo realizada por alunos, Santos (2018) traz uma abordagem semiautomática para auxiliar o processo de curadoria digital com foco em Recursos Educacionais Abertos (REA), em repositórios educacionais digitais inseridos em contextos institucionais, voltado principalmente aos seguintes indicadores de qualidade: "qualidade de conteúdo, alinhamento com os objetivos de aprendizagem, reputação do autor, reputação do docente utilizador e reusabilidade" (SANTOS, 2018, p. 49).

O autor explica que para validar um REA, utilizando tais indicadores, faz-se necessário quantificar. De modo geral, essa quantificação se dá por meio das expectativas do docente ao propor uma atividade e a coleta dos metadados de uso da experiência do estudante. Essa abordagem foi validada por meio de um experimento no contexto do Ensino Médico Técnico, com a participação de 56 alunos e 8 professores. Em linha gerais, os resultados revelaram que tanto a percepção do professor como a do aluno auxiliaram o processo de curadoria digital.

Ao tratar dos desafios da pesquisa qualitativa, frente às Tecnologias Digitais de Informação e Comunicação (TDIC), os estudos de Davidson (2012) abordam o contexto de um 
projeto de um jornal, a partir da combinação entre o uso de software de análise de dados qualitativos (NVivo), com a pesquisa baseada em artes, por meio do uso de diários pessoais (autoetnografia). Davidson (2012) revela que a partir das possibilidades de um CAQDA frente aos dados qualitativos de sua autoria, o tratamento e a manipulação dos dados foram os pontos fortes, além disso, segundo Lage e Godoy (2008), o uso de softwares como na análise qualitativa leva o pesquisador a estabelecer uma nova relação com seus dados. Entretanto, outras demandas surgem nesse contexto, como, por exemplo, o compartilhamento de dados, tanto em pesquisas qualitativas como em quantitativas.

Segundo Marques (2014), Machado (2015) e Resende (2019), essas demandas estão relacionadas ao paradigma científico emergente, conhecido como e-Science, que se configura como consequência das transformações provocadas pelas Tecnologias de Informação e Comunicação (TIC), as quais impactam nos padrões de comunicação científica, principalmente em relação às pesquisas colaborativas, que demandam compartilhamento e reuso de recursos informacionais, assim como as formas de comunicar e de disseminar os resultados de pesquisa.

Desta forma, a curadoria digital de dados de pesquisa está ganhando importância junto às instituições de pesquisa. Em várias comunidades científicas internacionais, o uso e prática das atividades de curadoria digital já vem sendo realizadas, sobretudo nas universidades de países como EUA, Reino Unido, Europa, Austrália, Ásia e continente africano (RESENDE, 2019).

Marques (2014) discute o contexto da curadoria digital de dados de pesquisa, na área de Ciências Nucleares, a qual tem uma tradição na organização, tratamento, interligação e disseminação da informação. Como principal resultado, o autor desenvolveu uma proposta de diretrizes para uma política nacional de curadoria digital e um modelo de publicação científica para a área de Ciências Nucleares, em que os dados são ligados às publicações acadêmicas por meio de relações semânticas sistematizadas em taxonomia construída para esta finalidade.

Machado (2015) trata do contexto de repositórios institucionais universitários Edinburgh DataShare, a partir de análises das relações estabelecidas entre diretrizes e práticas de gerenciamento de dados de pesquisa, baseando-se nas políticas de informação para um repositório institucional, levando em consideração as seguintes categorias: responsabilidade, conteúdos, aspectos legais, padrões, preservação digital, política de acesso e de uso, sustentabilidade e financiamento. Essas categorias, segundo Machado (2015), permitem visualizar as principais áreas para as quais as políticas devem ser definidas, lembrando que o contexto institucional deve ser priorizado. 
Resende (2019) descreve o cenário nacional da curadoria digital de dados de pesquisa, na área da Ciência da Informação, a partir do perfil dos pesquisadores, suas preferências e tendências da curadoria digital. Sobre o perfil dos pesquisadores, de modo geral, Resende (2019) constatou que existe movimentação para utilização de plataformas tecnológicas, confirmando, assim, a importância da curadoria digital de dados de pesquisa, nesses repositórios. Entretanto, as preferências apontam que pesquisadores não possuem familiaridade com a criação ou documentação de metadados, e que não conseguem prever as necessidades dos futuros reutilizadores de seus dados, processo essencial para o compartilhamento e reutilização dos dados. Por fim, os pesquisadores revelam que as tendências da curadoria digital no Brasil estão em fase de expansão e que passará a ser uma necessidade a partir da existência de uma diretriz nacional de dados científicos.

Kirilova e Karcher (2017), trazem o contexto de aplicação da curadoria digital a um Repositório de Dados Qualitativos (QDR). Os autores argumentam que embora esteja se tornando cada vez mais comum na investigação com dados quantitativos, os dados qualitativos raramente são compartilhados. Um fator que pode inibir tal compartilhamento refere-se à preocupação dos pesquisadores com a proteção e a privacidade dos participantes.

De qualquer forma, a proteção, a confidencialidade e a segurança dos participantes da pesquisa é uma preocupação tanto dos pesquisadores quantitativos como qualitativos; entretanto levanta questões específicas dentro do contexto epistêmico da pesquisa qualitativa. Nesse sentido, Kirilova e Karcher (2017) explicam que a aplicabilidade de modelos de proteção que emergem da abordagem da pesquisa quantitativa deve ser avaliada cuidadosamente para aplicação na abordagem qualitativa. Há algum tempo, os pesquisadores qualitativos já empregam uma variedade de estratégias para a proteção dos participantes humanos, implícita ou informalmente, durante o processo de pesquisa (KIRILOVA; KARCHER, 2017). A partir desse contexto, o artigo tem por objetivo descrever algumas opções de gerenciamento de dados, como desidentificação e aplicação de controles de acesso, incluindo alguns já empregados pelo Repositório de Dados Qualitativos (QDR).

Ao longo da discussão, Kirilova e Karcher (2017) consideram a tensão entre a modificação e/ou restrição de acesso aos dados e a retenção do seu valor analítico. Os autores argumentam que o desenvolvimento de diretrizes para o compartilhamento de dados qualitativos, gerados por meio da interação com seres humanos, poderá permitir que os pesquisadores abordem questões de privacidade e aumentem o uso secundário de seus dados.

A partir do exposto, soma-se o contexto das práticas de Gerenciamento de Dados de Pesquisa (RDM), por professores universitários por meio de desenho de pesquisa qualitativa, 
problematizado por Piracha e Ameen (2018). Os dados foram coletados por meio de entrevistas semiestruturadas com dez professores, a partir das seguintes indagações: Com que tipo de projetos de pesquisa os professores estão envolvidos e que quantidade e tipo de dados eles produzem? Quais são suas práticas de salvamento de dados e backup? Qual é a opinião deles sobre o compartilhamento de dados? Que tipo de suporte de gerenciamento de dados eles precisam? Quais são os principais problemas e desafios que eles enfrentam no RDM? Os resultados revelam preocupações relacionadas à quantidade de dados de pesquisa produzidos, o suporte necessário para a curadoria de dados e sua disposição em compartilhá-los, assim como necessidade de formação quanto ao armazenamento e segurança dos dados.

Por fim, vale pontuar que ao cotejar as diversas concepções e contextos de aplicação da curadoria digital adotadas nos estudos analisados, pretendeu-se uma discussão de caráter amplo, expondo as significações propostas por cada autor, de modo a elucidar as convergências presentes nas temáticas e possibilitar, principalmente, uma aproximação entre curadoria digital e gestão de dados em CAQDAS.

\section{Aproximações entre curadoria digital e gestão de dados em CAQDAS}

A curadoria digital, em CAQDAS, pode envolver a organização e a gestão de materiais digitais durante todo o processo da pesquisa qualitativa, tendo como perspectiva o desafio temporal de atender o gestor da pesquisa e seus colaboradores, o que engloba processos de organização das fontes, codificações, questionamentos e gestão da pesquisa, além de demandar a capacidade de adicionar valor a esses dados no sentido de gerar novas fontes de informação e de conhecimento. Mesmo não abordando o conceito de curadoria digital em CAQDAS, Marques (2014), Machado (2015) e Resende (2019), de modo mais geral, trazem reflexões sobre a curadoria de dados da pesquisa, que vem ganhando importância junto às instituições de pesquisa. Lage e Godoy (2008), de forma mais específica, trazem argumentos que vão ao encontro do processo de curadoria digital, tendo em vista que as autoras argumentam que para aproveitar todos os recursos disponíveis, é necessário utilizá-los desde o momento em que se inicia a investigação, ainda na fase de organização do referencial teórico, considerando os textos relacionados à teoria como um dos tipos de documentos.

Independente dos materiais digitais, conjunto de dados disponíveis e do tempo de duração de uma pesquisa qualitativa, a curadoria digital em CAQDAS deve assegurar que eles possam ser analisados e interpretados continuamente. Refletir sobre o processo de curadoria digital e, consequentemente, aplicá-la, pode minimizar a perda de informações, além de reforçar 
o valor a longo prazo dos dados existentes e os tornar disponíveis para a (re)utilização em novos contextos e/ou novas abordagens de pesquisa.

Sendo assim, o foco da curadoria digital na pesquisa qualitativa com CAQDAS está na gestão de todo o processo, que pode envolver o conceito de ciclo de vida dos materiais digitais, de forma que ele permaneça continuamente acessível e possa ser recuperado e (re)analisado, o que mostra-se fundamental em pesquisas qualitativas.

Para aplicar o processo de curadoria digital em CAQDAS, podemos recorrer aos modelos de ciclo de vida dos materiais digitais. Silva e Siebra (2017) identificaram sete modelos, os quais possuem, em sua gênese, a preocupação com a preservação de materiais no formato digital. As autoras explicam que os modelos são estruturalmente desiguais quanto à complexidade e detalhamento, entretanto desempenham funções similares quando se trata de procedimentos curatoriais e de preservação dos materiais digitais.

Para a reflexão sobre a questão da potencialidade da curadoria digital na pesquisa qualitativa com CAQDAS, optamos por abordar o modelo do Centro de Curadoria Digital (2019), principalmente por ser utilizado em diversos contextos, assim como a potencialidade para contribuir na organização e gestão das informações, além da possibilidade de definir as responsabilidades de gestores e colaboradores das pesquisas.

Vale pontuar que o ciclo de vida da curadoria digital proposta por esse modelo, compreende as seguintes etapas: conceituar; criar; acessar e utilizar; avaliar e selecionar; descartar; ingerir/ intervir; preservar; reavaliar; acessar e reutilizar; transformar (DCC, 2019). No intuito de aproximar esses conceitos à curadoria digital em CAQDAS, nos interessa refletir sobre como:

- Conceituar - nessa etapa cabe ao gestor da pesquisa, a concepção e planejamento do design da pesquisa, incluindo abordagens e métodos para a construção dos dados da pesquisa e opções de armazenamento nos CAQDAS, além da definição de políticas, requisitos legais e orientações para a criação e utilização de materiais digitais, informando como esses materiais serão utilizados e selecionados, assim como quais as permissões para acesso aos materiais.

- Criar - refere-se à organização, preparação e/ou produção de materiais digitais, além da definição dos parâmetros e atribuições para esses materiais, para organização das pesquisas qualitativas com CAQDAS.

- Acessar e utilizar - neste momento, o gestor da pesquisa deve certificar-se de que os colaboradores designados, possam acessar facilmente os materiais digitais da pesquisa. 
- Avaliar e selecionar - neste momento, tanto gestores como colaboradores da pesquisa, seguem os critérios definidos previamente na primeira fase, no intuito de avaliar os materiais digitais e selecionar aqueles que requerem curadoria e preservação, em outras palavras, verificar se os materiais cumprem os critérios de inclusão, orientações, políticas e requisitos legais documentados.

- Descartar - após a avaliação e seleção, os materiais digitais não selecionados para curadoria e preservação, que não atendem os critérios de inclusão para a pesquisa, podem ser descartados e/ou armazenados para análise posterior.

- Ingerir - consolidação dos materiais digitais da pesquisa, que atendem os critérios de inclusão da pesquisa, orientações documentadas, políticas e requisitos legais.

- Preservar - nessa fase, o gestor e os colaboradores podem empreender ações para garantir a preservação e retenção, a longo prazo, da natureza autorizada dos materiais digitais.

- Reavaliar - fase de reavaliação dos objetos que não estavam nos critérios definidos previamente, assim o gestor e os colaboradores da pesquisa podem retornar e/ou revisitar materiais digitais que, no momento da avaliação, não foram validados, mas podem ser (re)validados numa nova seleção.

- Armazenar - fase que leva em consideração a segurança de armazenamento dos materiais digitais; assim, cabe ao gestor e aos colaboradores manterem os dados da pesquisa de maneira segura, conforme descrito pelos padrões éticos vigentes.

- Acessar e reutilizar - em relação a essa fase, o gestor deve assegurar que os materiais da pesquisa estejam acessíveis aos colaboradores designados para (re)utilização; neste caso, o gestor pode autorizar o acesso e utilização de todos ou parte dos dados da pesquisa.

- Transformar - última fase considerada no ciclo da curadoria digital, a qual permite que novos objetos sejam criados dos critérios iniciais, levando em consideração a abordagem metodológica utilizada, e, assim, tanto o pesquisador responsável como os colaboradores, podem interferir nos dados, a partir das análises e, por isso, a especificação dessa transformação deve ser transparente para todos os envolvidos na pesquisa.

É importante ressaltar que, no contexto da pesquisa qualitativa em Educação, deve-se levar em consideração a abordagem e o design da pesquisa, assim os diferentes tipos de documentos que podem ser utilizados. Por isso, é preciso atentar para as particularidades 
inerentes a cada tipo de pesquisa em Educação para elaboração do processo de curadoria digital, a partir da utilização de CAQDAS.

Além disso, vale pontuar que os CAQDAS são desprovidos de capacidade analítica e, por isso, não substituem a intuição do pesquisador ou sua necessidade de fazer julgamentos (LAGE; GODOY, 2008; SILVA; ALMEIDA, 2017). O que eles possuem são recursos de gestão, organização, tratamento e consulta dos dados, carecendo da habilidade do pesquisador que deve problematizar sobre "o que" e "para que" consultar, "como" interpretar os resultados, "por que" e "a serviço do que" utilizar determinado recurso e/ou material para análise.

Essas são apenas algumas reflexões preliminares sobre como as ações de curadoria digital podem colaborar com a organização e gestão da pesquisa qualitativa com CAQDAS. Além disso, acresce a reflexão necessária sobre a sua utilização ética, pois, tornaram-se cada vez mais evidentes, nas últimas décadas, as preocupações éticas com as pesquisas qualitativas.

\section{Considerações Finais}

A respeito das possibilidades dos recursos dos CAQDAS, frente aos desafios da pesquisa qualitativa em educação, compreendemos que o software não pode ser visto como uma panaceia, conforme refletimos anteriormente. Os pesquisadores são os atores, neste caso, protagonistas do processo de curadoria digital. Os CAQDAS, se bem utilizados, podem facilitar o gerenciamento dos arquivos, agilizar a codificação e busca de respostas, além de facilitar a comunicação entre os participantes da pesquisa. Entretanto, quem decide a curadoria digital (conceituação; criação; acesso e utilização; avaliação e seleção; descarte; intervenção; preservação; reavaliação; acesso e reutilização; transformação), continua sendo o pesquisador, a partir também das problematizações sobre como, por que, o que, para que e a serviço do que se deve utilizar os CAQDAS.

É pertinente considerar, também, que os desafios a serem enfrentados na implementação de práticas de curadoria digital em CAQDAS, são inúmeros; porém, devem ser enfrentados por investigadores qualitativos, que disponibilizam e compartilham seus dados de pesquisa em CAQDAS.

A adoção da curadoria digital em CAQDAS se mostra em sinergia com as demandas atuais da pesquisa qualitativa. Entretanto, esse processo poderá provocar questionamentos e gerar insegurança nos pesquisadores, pois trazem novas perspectivas e requerem o repensar das formas de organizar e fazer a gestão das pesquisas. 
Vale pontuar, ainda, que essa revisão sistemática de literatura refere-se à um estudo inicial sobre as aproximações entre curadoria digital e gestão de dados em CAQDAS, apresentando limitações já que nossas considerações foram realizadas a partir das bases teóricas disponíveis na Scopus e Catálogo de Teses e Dissertações da Capes, usando os termos Digital AND curation; digital AND curation AND cloud AND software; "qualitative analysis" AND curation; curation AND software

Por fim, vale salientar que não é pretensão deste trabalho encerrar as reflexões, mas contribuir com a construção do conhecimento acerca de tal temática. Como trabalhos futuros, recomenda-se, realizar uma pesquisa empírica com investigadores qualitativos, que utilizam CAQDAS, dentro do contexto dos processos de curadoria digital, no intuito de identificar as estratégias e critérios de curadoria digitais que tais pesquisadores utilizam em investigações qualitativas em educação.

\section{REFERÊNCIAS}

ANDRADE, L. R.; COSTA, A. P.; LINHARES, R. N.; DE ALMEIDA, C. A.; REIS, L. P. Qualitative Data Analysis Software Packages: An Integrative Review. In: COSTA, A.; REIS, L.; MOREIRA, A. (Eds). Computer Supported Qualitative Research. WCQR 2018. Advances in Intelligent Systems and Computing, vol 861. Springer, Cham, 2019.

BARROS, M. de L. T.; MARCONDES, M. I. Ética e Pesquisa em Educação: uma discussão necessária. Cadernos de Pesquisa, 49(171), 332-337, 2019.

*1 BARTON, David. The roles of tagging in the online curation of photographs. Discourse, context \& media, v. 22, p. 39-45, 2018.

* CHAGAS, Alexandre Meneses; LINHARES, Ronaldo Nunes e MOTA, Marlton Fontes. A curadoria de conteúdo digital enquanto proposta metodológica e multirreferencial. RISTI [online]. 2019, n.33, pp.32-47.

* CORTI, L.; WELPTON, R. Access to sensitive data for research: "The 5 Safes". Data Impact Blog, 2015. Disponível em: <https://www.ukdataservice.ac.uk/manage-data/legalethical/access-control/five-safes>. Acesso em: 10 mar. 2021.

COSTA, A. P.; MOREIRA, A.; SOUZA, F. N. de. webQDA - Qualitative Data Analysis. Aveiro: MicroIO and University of Aveiro, 2019.

CRESWELL, J. W. Projeto de pesquisa: método qualitativo, quantitativo e misto. Porto Alegre: ArtMed, 2010.

\footnotetext{
${ }^{1}$ As referências bibliográficas sinalizadas com um asterisco $(*)$ referem-se às que fazem parte do corpus de análise da revisão sistemática de literatura.
} 
* DAVIDSON, Judith. The journal project: Qualitative computing and the technology/aesthetics divide in qualitative research. Forum Qualitative Sozial Research, v. 13, n. $2,2012$.

DCC. DIGITAL CURATION CENTRE. Disponível em: <https://www.dcc.ac.uk/about/digital-curation>. Acesso em: 25 fev. 2021.

DE ALMEIDA, C. A.; FREITAS, F., COSTA, A. P.; MOREIRA, A. WEBQDA: The Quest for a Place in the Competitive World of CAQDAS. In: 2019 International Conference in Engineering Applications (ICEA). IEEE, 2019. p. 1-7.

FORNARI, Lucimara Fabiana; PINHO, Isabel; COSTA, António Pedro. Review of Literature with Support of webQDA Software. In: 2019 14th Iberian Conference on Information Systems and Technologies (CISTI). IEEE, 2019. p. 1-6.

* KANKE, Timothy. Knowledge curation work in Wikidata WikiProject discussions. Library Hi Tech, 2019.

* KIRILOVA, Dessi; KARCHER, Sebastian. Rethinking data sharing and human participant protection in social science research: Applications from the qualitative realm. Data Science Journal, v. 16, 2017.

LAGE, Maria Campos; GODOY, Arilda Schmidt. O uso do computador na análise de dados qualitativos: questões emergentes. RAM, Rev. Adm. Mackenzie, São Paulo, v. 9, n. 4, p. 75-98, Junho de 2008. Disponível em:

$<$ http://www.scielo.br/scielo.php?script=sci_arttext\&pid=S1678-

69712008000400006\&lng=en\&nrm=iso>. Acesso em: 10 mar. 2021.

* MAIA, Louise Pereira. Curadoria Digital em Bibliotecas: uma aplicação do modelo do DCC no planejamento de criação da Biblioteca MUSAL Digital. 2019. 145 f. (Mestrado Profissional em Biblioteconomia). Universidade Federal do Estado do Rio de Janeiro, Rio de Janeiro, 2019.

* MACHADO, Denise Ramires. Dados de pesquisa em repositório institucional: o caso do Edinburgh. 2015. 113 f. (Mestrado em Comunicação e Informação) - Universidade Federal do Rio Grande do Sul, Porto Alegre, 2015.

MANOVICH, L. The Language of New Media. Cambridge: The MIT Press, 2001.

* MARQUES, Luana Farias Sales. Integração semântica de publicações científicas e dados de pesquisa: proposta de modelo de publicação ampliada para a área de Ciências Nucleares. 2014264 f. (Doutorado em Ciência da Informação) - Universidade Federal do Rio de Janeiro, Rio de Janeiro, 2014.

* MELLO, A. F. A curadoria de informação aplicada ao jornalismo: uma análise comparativa de aplicativos móveis. 151 f. Dissertação (Mestrado) - Pontifícia Universidade Católica do Rio Grande do Sul. Faculdade de Comunicação Social. Programa de PósGraduação em Comunicação Social, 2015.

MINAYO, M. C.; COSTA, A. P. Técnicas que fazem uso da palavra, do olhar e da empatia. Aveiro: Ludomedia, 2019. 
NÓBREGA-THERRIEN, S.; THERRIEN, J. O estado da questão: sua compreensão na construção de trabalhos científicos: reflexões teórico-metodológicas. Estudos em Avaliação Educacional, v. 15, n. 30, p. 5-16, jul./dez. 2004.

* PIRACHA, Haseeb Ahmad; AMEEN, Kanwal. Research Data Management Practices of Faculty Members. Pakistan Journal of Information Management and Libraries, v. 20, p. 60-75, 2018.

RAMOS, Altina; FARIA, Paulo M.; FARIA, Ádila. Revisão sistemática de literatura: contributo para a inovação na investigação em Ciências da Educação. Revista Diálogo Educacional, v. 14, n. 41, p. 17-36, 2014.

* RESENDE, Liliane Chaves de. A curadoria de dados científicos na ciência da informação: levantamento do cenário nacional. 2019133 f. (Mestrado em Gestão e Organização do Conhecimento) - Universidade Federal de Minas Gerais, Belo Horizonte, 2019.

* SANTOS, Marcelo dos. CREDItoR: Uma abordagem semiautomática para curadoria em repositórios educacionais digitais com foco em recursos educacionais abertos'. 2018. $174 \mathrm{f}$. (Mestrado em Ciência da Computação). Instituição de Ensino: Universidade Federal de São Carlos, São Carlos Biblioteca Depositária: BCo - UFSCar, 2018.

* SANTOS, Thayse Natalia Cantanhede. Curadoria digital: o conceito no período de 2000 a 2013. 2014. 166 f. (Mestrado em Ciências da Informação). Instituição de Ensino:

Universidade de Brasília, Brasília, 2014.

SAYÃO, L. F.; SALES, L. F. Curadoria digital: um novo patamar para preservação de dados digitais de pesquisa. Informação \& Sociedade: Estudos, v.22, n.3, p. 179-191, set./dez, 2012.

SILVA, Faysa Maria de Oliveira; SIEBRA, Sandra de Albuquerque. Análise de modelos de ciclos de vida para curadoria de objetos digitais. In Encontro Nacional de Pesquisa em Ciência da Informação, v. 18, 2017.

SILVA, K. A. G.; ALMEIDA, M. E. B. Combined use of software that supports research and qualitative data analysis: potential applications for researches in education. In COSTA, A.; REIS, L.; NERI DE SOUZA, F.; MOREIRA, A.; LAMAS, D. (Eds). Computer supported qualitative research. Studies in systems, decision and control, v. 71. Springer, Cham, 2017.

SILVA, K. A. G.; COSTA, A. P. Processo de escolher/avaliar materiais didáticos digitais: concepções e implicações de professores. Revista EDaPECI, São Cristóvão (SE), v.19, n.1, p. 121-136, jan./abr, 2019.

* SOUZA, Ericka Madeira de. A curadoria digital e o reuso dos acervos culturais digitais da Rede Web de Museus do Estado do Rio de Janeiro. 2018. 125 f. (Mestrado Profissional em Memória e Acervos). Fundação Casa de Rui Barbosa, Rio de Janeiro, 2018.

* SOUZA, Thales Vicente de. Curadoria Digital: um novo espaço de atuação do profissional de informação. 2016. 102 f. (Mestrado em Ciência da Informação). Instituição de Ensino:

Universidade Federal Fluminense, Niterói, 2016. 
SOUZA, F. N.; COSTA, A. P.; MOREIRA, A. Questionamento no processo de análise de dados qualitativos com apoio do software webQDA. EduSer - Revista de Educação, 3(1), 19-30, 2011a.

SOUZA, F. N.; COSTA, A. P.; MOREIRA, A. Questioning in the Qualitative Research Process. How ICT can support this process?. In 4o Congresso Ibero-Americano de Investigação Qualitativa. Aracaju, 2015. Acesso em: <https://proceedings.ciaiq.org/index.php/ciaiq2015/article/view/166>. Acesso em: 10 mar. 2021.

SOUZA, F. N.; SOUZA, D. N. de; COSTA, A. P. Asking questions in the qualitative research context. The Qualitative Report, v. 21, n. 13, p. 6-18, 2016.

VALENTE, J. A. O uso do CHIC na pesquisa. In: VALENTE, J. A.; ALMEIDA, M. E. B. Uso do Chic na formação de educadores. Letra Capital Editora LTDA, 2015.

WEBER, C. Curadoria digital de dados científicos: pelo viés de um periódico. P2P e Inovação, 3(1), 130-147, 2016.

\section{SOBRE OS AUTORES:}

Katia Alexandra de Godoi e Silva

Pós-doutoranda no Centro de Investigação em Didática e Tecnologia na Formação de Formadores (CIDTFF) da Universidade de Aveiro (Portugal). Doutora em Educação e Currículo pela PUC-SP. Docente do Programa de Metodologias para o Ensino de Linguagens e suas Tecnologias - Unopar e do Mestrado em Ensino de Ciências e Matemática - Uniderp. Correio eletrônico: katia.a.silva@anhanguera.com

(iD) https://orcid.org/0000-0002-6003-6852

\section{António Pedro Costa}

Doutor em Multimédia em Educação pela Universidade de Aveiro. Investigador do Centro de Investigação em Didática e Tecnologia na Formação de Formadores (CIDTFF), Departamento de Educação e de Psicologia, da mesma universidade. Investigador do software webQDA. Coordenador do Congresso Ibero-Americano em Investigação Qualitativa (CIAIQ).

Correio eletrônico: pcosta@ludomedia.pt

(iD https://orcid.org/0000-0002-4644-5879 